\title{
Spatial distribution pattern, bionomic, and demographic parameters of a new invasive species of armyworm Spodoptera frugiperda (Lepidoptera; Noctuidae) in maize of South Sumatra, Indonesia
}

\author{
RUDI TOMSON HUTASOIT ${ }^{1}$, SEPTIAN HARY KALQUTNY ${ }^{2, \boldsymbol{v}}$, I NYOMAN WIDIARTA ${ }^{\mathbf{3}}$ \\ ${ }^{1}$ Tungro Research Disease Station. Jl. Bulo No. 101, Lanrang, Sidenreng Rappang 91652, South Sulawesi, Indonesia \\ ${ }^{2}$ Indonesian Cereals Research Institute. Jl. Dr. Ratulangi No. 274, Maros 90514, South Sulawesi, Indonesia. Tel.: +62-411-371529-371016, \\ Fax.: +62-411-371961, `email: septianharykalqutny@gmail.com \\ ${ }^{3}$ Indonesian Center for Food Crops Research and Development. J1. Merdeka No.147, Bogor 16111, West Java, Indonesia
}

Manuscript received: 27 May 2020. Revision accepted: 15 July 2020

\begin{abstract}
Hutasoit RT, Kalqutny SH, Widiarta IN. 2020. Spatial distribution pattern, bionomic, and demographic parameters of a new invasive species of armyworm Spodoptera frugiperda (Lepidoptera; Noctuidae) in maize of South Sumatra, Indonesia. Biodiversitas 21: 3576-3582. The fall armyworm, Spodoptera frugiperda, has reportedly been found in Indonesia since 2019. The main hosts of this new invading insect are food crops and several other crops. This study aimed to examine the spatial distribution pattern, bionomic, and demographic parameters for developing a sampling plan and strategy to control the pest. The study was conducted by observing the total population of $S$. frugiperda on nine plots of maize plants weekly. The development of $S$. frugiperda from egg to adult was also observed in plastic containers (diameter of $4 \mathrm{~cm}$ x height of $8 \mathrm{~cm}$ ) fed with maize in controlled room conditions (temperature $=29 \pm 2.1^{\circ} \mathrm{C}, 74 \pm$ $10.1 \% \mathrm{RH})$. Observations were made on several bionomic and demographic parameters. The results of the study showed that the $S$. frugiperda distributes in groups, and each group spreads with a low grouping rate. The life cycle of $S$. frugiperda occurs for an average of 25.11 days with a range of 24-26 days. The net reproduction rate (Ro) of $S$. frugiperda was 422.46 individuals/parent/generation. $S$. frugiperda's intrinsic rate of increase was 0.22 individuals/parent/day. The length of generation (T) and $S$. frugiperda doubling time (DT) were 26.59 and 3.04 days, respectively. This species has survived well on the maize in the new habitat, so it will threaten the food crops, especially the maize. A sampling plan can be developed based on spatial distribution parameters to monitor population density to implement a control threshold and control measures from the early stage of maize during adult pre-emergence.
\end{abstract}

Keywords: Bionomic parameter, demographic parameter, fall armyworm, spatial distribution pattern

\section{INTRODUCTION}

Fall armyworm (Spodoptera frugiperda J.E. Smith) is a pest originated from the tropical and subtropical region of America (Baloch et al. 2020), where it is a serious pest of corn and also known to attack more than 100 hosts (Sharanabasappa et al. 2018). S. frugiperda was first reported in the African continent in early 2016 (Goergen et al. 2016; Cock et al. 2017). In 2018, this pest was reported to have attacked the maize crop in India (Sharanabasappa et al. 2018; Sidana et al. 2018). Nonci et al. (2019) reported that this pest has entered and attacked the maize plantation in Indonesia, precisely in Koto Baru, Luhak Nan Duo West Pasaman, West Sumatra. This pest quickly spread to several locations in Indonesia (Maharani et al. 2019; Lestari et al. 2020). Based on the survey results conducted to farmers, the damage and loss of yield caused by $S$. frugiperda in maize plantations in Africa were reported to be very serious. This pest has caused estimated losses of up to 250-630 million US dollars per year (Bateman et al. 2018). Day et al. (2017) revealed that $22 \%-67 \%$ of damage occurred in Ghana and Zambia, causing the loss up to millions of dollars. Up to $32 \%$ and $47 \%$ of the damage was reported in Ethiopia and Kenya (Kumela et al. 2018). Baudron et al. (2019) mentioned that the estimated damage in Zimbabwe was $11.57 \%$.

Fall armyworm is classified as a polyphagous pest. Although it has a preference for the Poaceae family, this pest has a broad range of hosts and can attack several other types of plants (Barros et al. 2010; Kergoat et al. 2012). This causes polyphagous pests such as $S$. frugiperda to be able to utilize various other types of hosts to develop in the conditions where the main host is not available, and then it might migrate to the plantation area in which the main host is available again (Montezano et al. 2018). S. frugiperda adults can move up to $806.2 \mathrm{~m}$ and is likely to move further depending on the condition around the plant stage, oviposition site, food source, the availability of mate, and any other factors (Vilarinho et al. 2011; Nagoshi et al. 2012).

Fall armyworms cause damage to plants by eating the leaves. As a consequence, it may interfere with the plant photosynthesis, damage the plant growth structure and reproduction, or damage the cob directly (Chimweta et al. 2019). There are several types of symptoms of plant damage caused by $S$. frugiperda, that the early instar is usually eating by leaving some semitransparent parts on leave. Instar with later stage tends to enter and eat the leaf whorl in maize, so the typical symptoms of leaves with holes become more apparent along with the development of 
plants. That eating preference at the plant's growing point may inhibit plant growth and sometimes lead to lethal damage. In older plants, the late-stage instar may damage the maize cobs so it can reduce the quality and yields obtained (Sisay et al. 2019).

The information about the biology of $S$. frugiperda in Indonesia is still limited. The study about the spatial distribution pattern, bionomic, and demographic parameters of $S$. frugiperda are important to determine the distribution patterns and growth rates of these pest populations. Further information is needed as a basis for developing a sampling plan and the strategy to control this pest in order to reduce the risk of damage and loss of maize yields. Therefore, this study aimed to determine the spatial distribution pattern, bionomic, and demographic parameters of $S$. frugiperda at their new habitat in Indonesia.

\section{MATERIALS AND METHODS}

\section{Spatial distribution pattern analysis}

The study was conducted in July-August 2019 in a maize field in a wetlands area, located in Tirtaharja Village, Muara Sugihan Sub-district, Banyuasin District, South Sumatra, Indonesia. Observations were made on a total of nine plots, each measuring $1.5 \times 2.5 \mathrm{~m}^{2}$ with a plant spacing of $70 \times 20 \mathrm{~cm}^{2}$ set up. Visual observations and a population count of the $S$. frugiperda were carried out on 30 plants in each plot weekly for four consecutive weeks by recording the number of individuals of $S$. frugiperda larvae in each plant. Observations were made without harming the plant or $S$. frugiperda larvae. The S. frugiperda spatial distribution pattern between the mean density $(\mathrm{m})$ and mean crowding $\left(\mathrm{m}^{*}\right)$ number of larvae in each plot for four consecutive weeks was analyzed by using Iwao's linear regression analysis (Iwao et al. 1968). The mean crowding is calculated using the formula:

$$
\mathrm{m}^{*}=\sum_{\mathrm{i}=1}^{\mathrm{n}}\left(\mathrm{x}_{\mathrm{i}}-1\right) \mathrm{x}_{\mathrm{i}} / \sum_{\mathrm{i}=1}^{\mathrm{n}}\left(\mathrm{x}_{\mathrm{i}}\right)
$$

Where; $\mathrm{x}_{\mathrm{i}}$ is the number of individuals in each plot and $\mathrm{n}$ is the total number of plots. The relation $\mathrm{m}^{*}-\mathrm{m}$ is shown by the regression as:

$$
\mathrm{m}^{*}=\alpha+\beta \mathrm{m}
$$

Where; an intercept $\alpha$ is an index of basic contagion, and the slope $\beta$ is a density-contagiousness coefficient.

\section{Propagation of Spodoptera frugiperda}

Propagation of $S$. frugiperda and test plants were carried out in a greenhouse at Balai Penyuluhan Pertanian in Muara Sugihan Sub-district, Banyuasin District, South Sumatra. The late instar larvae of $S$. frugiperda, which were used as the initial insect population, were collected from the maize fields in Tirtaharja Village, Muara Sugihan Sub-district, Banyuasin District. A total of 100 late instar larvae were kept in plastic cages (diameter of $15 \mathrm{~cm} \mathrm{x}$ height of $25 \mathrm{~cm}$ ) and were fed daily with the maize leaves until they reached the pupal stage. The adults obtained from previous propagation were kept in confinement (diameter of $30 \mathrm{~cm} \mathrm{x}$ height of $60 \mathrm{~cm}$ ) with the inner surface covered with paper as a medium to lay eggs. The adults were fed with a solution of $10 \%$ honey/water (wt/vol) by soaking cotton rolls in the solution then placed in a plastic container in a cage that was replaced every day.

\section{Observation of bionomic and demographic parameters}

A total of 100 eggs in a cohort population from previous propagation were kept on maize leaves in plastic cages (diameter of $4 \mathrm{~cm} \times$ height of $8 \mathrm{~cm}$ ). The number of larvae that lived died, and molted was observed and recorded daily until the adult stage. The larval development from first to the sixth instar was separated from each stage by molting and was marked by the presence of exuviae (Figure 1). Maize leaves were replaced every day. The newly emerged adults were identified and the data of the sex ratio were collected as well as the data of the stage duration of $1^{\text {st }}-6^{\text {th }}$ instar.

The longevity of male and female adults was observed separately in an insect cage $(30 \mathrm{~cm} \times 60 \mathrm{~cm})$. Each cage was infested with one adult male. The female adult was observed by maintaining an adult in an insect cage with the paper as the oviposition media. Each cage was infested with a female adult and two male adults. Female and male adults were transferred to new cages every day. The transfers were carried out every day until the last female adults were dead. The number of eggs produced by each female adult was calculated every day. Adults were fed with a solution of $10 \%$ of honey/water (wt / vol) by soaking cotton rolls in the solution then placed in a plastic container in a cage that was replaced every day until the male and female adults were dead.

The parameters observed including (i) development of the egg to first instar larvae; (ii) duration of development of $1^{\text {st }}-6^{\text {th }}$ instar larvae; (iii) the duration of development from the 6th instar larvae to pupae; (iv) the duration of development from pupae to adults; (v) life span of the adults; (vi) pre-oviposition and oviposition periods; and (vii) the number of eggs laid.

\section{Analysis of demographic parameters}

Data of the longevity and fecundities were compiled in the form of statistical demographics (life table). The life table can provide a detailed description of the growth rate (birth, development, reproduction, and death) of each individual in a population (Hutasoit et al. 2017). The data collected were: (i) $\mathrm{x}$ is cohort age class (days), (ii) $\mathrm{lx}$ is the chance of a life of each individual at age $\mathrm{x}$, (iii) $\mathrm{mx}$ is fecundity per individual at age $\mathrm{x}$, (iv) $1 \mathrm{xmx}$ is the number of offspring born in the age class $x$. The calculation was made by using the Jackknife method, which is a calculation technique by removing one observation data repeatedly (resampling). The Jackknife method was used as a general approach to test the hypotheses and calculate the confidence intervals. The demographic parameters observed were; (i) Gross reproduction rate (GRR) $=\Sigma \mathrm{mx}$, 
(ii) net reproduction rate $(\mathrm{R} 0)=\Sigma 1 \mathrm{xmx}$, (iii) intrinsic rate of increase (r) $=\ln (\mathrm{R} 0) / \mathrm{T}$, (iv) average generation time ( $\mathrm{T})=\Sigma \mathrm{xlxmx} / \Sigma \mathrm{lxmx}$, and (v) doubling time $(\mathrm{DT})=\ln$ $(2) / r$.

\section{RESULTS AND DISCUSSION}

\section{Spatial distribution pattern of Spodoptera frugiperda}

Regression analysis between the mean density (m) and mean crowding $\left(\mathrm{m}^{*}\right)$ in Table 1 described the spatial distribution pattern of the $S$. frugiperda sample population in the field. The intercept of regression values was greater than 0 , and the regression slope value was around 1 .

\section{Bionomic parameters of Spodoptera frugiperda in maize}

Daily observations results showed that the average life cycle of $S$. frugiperda lasted for 25.11 days, with a range of 24-26 days (Table 2). The life cycle duration of $S$. frugiperda in this study was shorter than reported by Murua and Virla (2004) and Sharanabasappa et al. (2018). The larvae developmental period to the pupal stage for the male tend to longer than female, and the pupal stage duration for the male was significantly longer than female. The beet armyworm, S. exigua reared on different host plants including maize also shown larvae development period for male longer than female (Farahani et al. 2011). Interestingly, the tendency for males to emerge after females of the armyworm is not common in insects with discrete, nonoverlapping generations (Bulmer 1983). In the opposite of the larvae period, female adults longevity was significantly longer than male adults. A similar trend on the longevity of female $S$. exigua was reported by MardaniTalaei et al. (2012). The sex ratio of $S$. frugiperda in maize plants was 1: 1.72 (female: male). A higher number of males compared to females in this study might be affecting the preimaginal stage duration of the male. Similar results were also reported in Guinea grass, where the ratio of females and males is 1: 1.5 (Murua and Virla 2004).

\section{Survivorship and fecundity of Spodoptera frugiperda on maize}

Daily survivorship and fecundity of $S$. frugiperda are presented in Table 3 and Figure 2. The survivorship of $S$. frugiperda showed that the chances of survival began to decline when entering the sixth instar larvae and pupal stage (Table 3). The highest mortality occurred during adult. The survivorship curve from daily observations suggested that the $S$. frugiperda survival type has a type I pattern. Type I curves describe the death of small numbers of organisms in the early population and higher numbers of deaths in the later stage of the population (Price 1997). High mortality in later stages will result in a higher population in the next generation compared to high mortality in the early stage.

Fecundity curve of $S$. frugiperda showed that the egglaying began on the 25th day after the infestations (Figure 2 ). The female adult preoviposition period lasted for 3-4 days, while the oviposition period lasted for 2-8 days. The average fecundity of adult females reached the peak of the curve on the 27th day after the infestation (350.89). The female adult of $S$. frugiperda laid eggs in large quantities in the early phase of adults and the number continued to decrease along with age and it fluctuated again before adult's death.

\section{Demographic parameters of Spodoptera frugiperda in maize plants}

The demographic parameters of $S$. frugiperda consisted of Gross Reproduction Rate (GRR), Net Reproduction Rate (Ro), Intrinsic Rate of Increase (r), Average Generation Time (T), and Doubling Time (DT) (Table 4). Ro and $r$ values obtained were lower than the ones reported by Murua and Virla (2004) using corn as food source. The lower Ro and $r$ values in this study might be influenced by the fewer number of females compared to males. However, the $\mathrm{T}$ value in this study is lower, the lower $\mathrm{T}$ value illustrates the faster reproduction rate of an organism.

Table 1. Regression statistics of Iwao's mean crowding and mean density to describe spatial distribution pattern of Spodoptera frugiperda population sample

\begin{tabular}{|c|c|c|c|c|c|c|c|c|}
\hline \multirow{2}{*}{ Data source } & \multirow{2}{*}{$n$} & \multicolumn{3}{|c|}{ Intercept } & \multicolumn{3}{|c|}{ Slope } & \multirow{2}{*}{$r^{2}$} \\
\hline & & $\alpha \pm S E$ & t Stat & P-value & $\beta+\mathrm{SE}$ & t Stat & P-value & \\
\hline $\begin{array}{l}\text { S. frugiperda field } \\
\text { population of } \\
\text { Tirtaharja Village, } \\
\text { Muara Sugihan Sub- } \\
\text { district, Banyuasin } \\
\text { District, South } \\
\text { Sumatra in } 2019\end{array}$ & 36 & $-0.399 \pm 0.139$ & -2.883 & $<0.01$ & $1.216 \pm 0.068$ & 17.849 & $<0.001$ & 0.904 \\
\hline
\end{tabular}




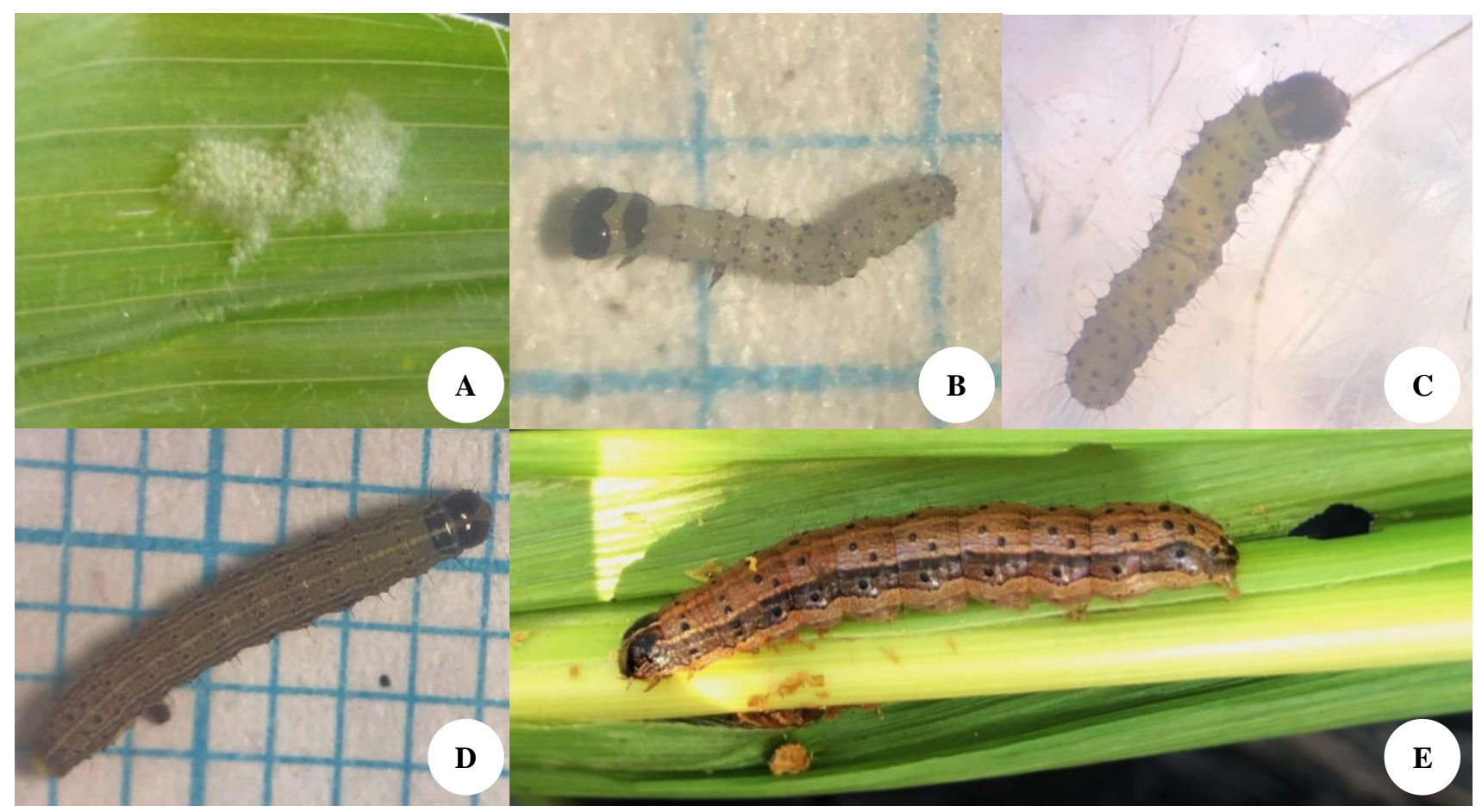

Figure 1. Egg and larval stage of Spodoptera frugiperda. A. Egg, B. $1^{\text {st }} \operatorname{lnstar}$, C. $2^{\text {nd }}$ instar, D. $3^{\text {rd }}$ instar, E. $6^{\text {th }}$ instar. arrow: inverted Y shape on the head, circle: four black dots (pinacula) in the eighth segment

Table 2. Bionomic parameters of Spodoptera frugiperda in maize

\begin{tabular}{|c|c|c|}
\hline Parameters & $\begin{array}{c}\text { Mean } \pm \mathrm{SE} \\
(\text { days/eggs) }\end{array}$ & $\begin{array}{l}\text { Range } \\
\text { (days/eggs) }\end{array}$ \\
\hline Egg incubation & $2.62 \pm 0.08$ & $2-3$ \\
\hline \multicolumn{3}{|l|}{$1^{\text {st }}$ to $6^{\text {th }}$ instar period } \\
\hline Female & $12.69 \pm 0.16$ & $11-15$ \\
\hline Male & $12.84 \pm 0.15$ & $11-15$ \\
\hline \multicolumn{3}{|l|}{ Pupal stage } \\
\hline Female & $6.31 \pm 0.08$ & $5-7$ \\
\hline Male & $6.76 \pm 0.12$ & $5-9$ \\
\hline Life cycle & $25.11 \pm 0.11$ & $24-26$ \\
\hline Pre-oviposition phase & $3.33 \pm 0.07$ & $3-4$ \\
\hline Fecundity & $1165.83 \pm 43.6$ & $766-1572$ \\
\hline \multicolumn{3}{|l|}{ Longevity of the adults } \\
\hline Female & $10.06 \pm 0.33$ & $7-16$ \\
\hline Male & $8.60 \pm 0.28$ & $6-14$ \\
\hline
\end{tabular}

Table 3. The survivability and stage durations of Spodoptera frugiperda on maize

\begin{tabular}{lcc}
\hline Stage & $\begin{array}{c}\text { Number of } \\
\text { individuals }\end{array}$ & $\begin{array}{c}\text { Stage duration } \\
\text { (days) }\end{array}$ \\
\hline Egg & 100 & $2-3$ \\
$1^{\text {st }}$ Instar & 100 & $2-3$ \\
$2^{\text {nd }}$ Instar & 100 & $2-3$ \\
$3^{\text {rd }}$ Instar & 100 & $1-3$ \\
$4^{\text {th }}$ Instar & 100 & $2-3$ \\
$5^{\text {th }}$ Instar & 100 & $1-2$ \\
$6^{\text {th }}$ Instar & 99 & $2-4$ \\
Pupa & 98 & $5-9$ \\
Adults & 98 & $6-16$ \\
\hline
\end{tabular}

Table 4. Demographic parameters of Spodoptera frugiperda

\begin{tabular}{ll}
\hline \multicolumn{1}{c}{ Parameters } & \multicolumn{1}{c}{ Mean \pm SE } \\
\hline & \\
Gross Reproduction Rate (GRR) & $1233.94 \pm 0.48$ ind./generation \\
Net Reproduction Rate (Ro) & $422.46 \pm 0.59$ ind./parent/generation \\
Intrinsic Rate of Increase (r) & $0.22 \pm 0.00$ ind./parent/generation \\
Generation Time (T) & $26.59 \pm 0.00$ days \\
Doubling Time (DT) & $3.04 \pm 0.00$ days \\
\end{tabular}

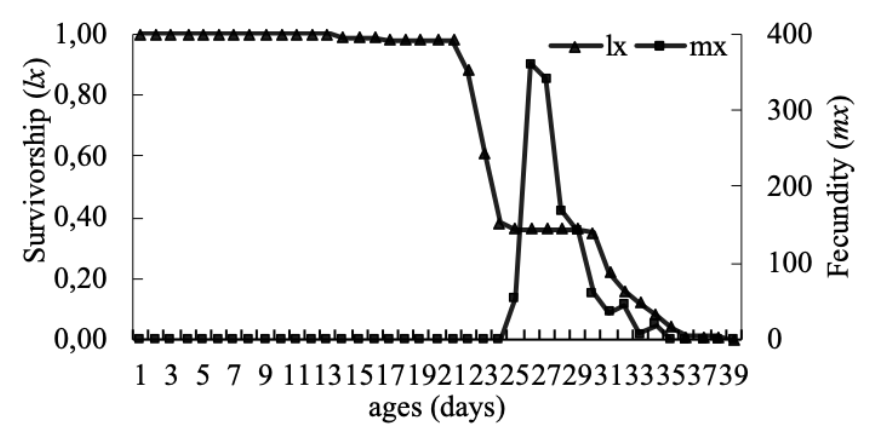

Figure 2. Survivorship (lx) and fecundity (mx) of Spodoptera frugiperda on maize 


\section{Discussion}

The mean crowding value represents the average number of other individuals per individual in a unit of space (Wade et al. 2018). The intercept of regression values in this study was greater than 0 . This indicated that armyworms spread in groups (consisting of several individuals), and the groups spread with a low grouping rate on the fields because the regression slope value is around 1 . The spatial distribution pattern obtained from this study was similar to the study conducted by Rios et al. (2014) in Southern Pernambuco state, Brazil, as well as the study result of Nava et al. (2018). Intercept values $(\alpha)$ that are positive or greater than 0 might be due to the behavioral preferences of $S$. frugiperda that prefer certain spots in their habitat (leaf whorl) plus their characteristics of laying eggs in a group. The regression slope $(\beta)$ describes the distribution pattern of individuals and groups of individuals in space, which is related to population density (Iwao et al. 1968). Accurate sampling design for monitoring to implement an action threshold and for studying population dynamics can be arranged based on spatial distribution patterns (Butler and Trumble 2012; Widiarta 1995; Iwao 1975; Kuno 1969).

The short incubation period of the eggs, $1^{\text {st }}-6^{\text {th }}$ instar larvae and pupae will shorten the overall life cycle period of this pest. A short life cycle indicates that maize is indeed a suitable host for the development of $S$. frugiperda. This is in accordance with Hay-Roe et al. (2016) who reported that $S$. frugiperda caused damage to various types of crops, especially maize, sorghum, rice, and various types of grass. It was further explained that there were two strains of $S$. frugiperda. Both strains are morphologically identical but differed in ecology, genetics, and physiology (Saldamando and Velez-Arango 2010). One strain identified as strain C (maize strain), mainly attacks maize plant, while another strain was identified as strain $\mathrm{R}$ (rice strain) attacking rice and grasses.

Optimum temperature and humidity conditions during the rearing may shorten the life cycle of $S$. frugiperda. Kondidie (2011) reported that $S$. frugiperda completes its life cycle about 30 days during the summer. The duration of the life cycle increases to 60 days in spring and autumn, while in winter, it can reach 80-90 days. The average room temperature and relative humidity during the study were 29 $\pm 2.1^{\circ} \mathrm{C}$ and $74 \pm 10.1 \%$, respectively. The life cycle of $S$. frugiperda in this study, which was observed to be shorter than previous reports from other parts of the world, may indicate a higher level of risk on the spread and attack in the tropics with optimum conditions, particularly Indonesia compared to regions with other climates.

The average number of eggs placed by an S. frugiperda female adult was $1,165.83 \pm 43.6(766-1,572)$ eggs. Murua and Virla (2004) reported that the average fecundity of adult females by feeding a mixture of honey/water (1: 1 $\mathrm{vol} / \mathrm{vol}$ ) was $1,044 \pm 411$ in the temperature range of $25 \pm 2$ ${ }^{\circ} \mathrm{C}$, and the humidity of $70-75 \%$. Sharanabasappa et al. (2018) further reported that the average fecundity of adult females by feeding honey $10 \%$ is $1,064.80 \pm 109.53$ (835.00-1169.00) eggs. The difference in the number of eggs produced by $S$. frugiperda female adults might be influenced by temperature (Combs and Vilario 1980). Berger et al. (2008) explained that in conditions of high temperatures the female adults will divert its energy to produce more eggs, while at low temperatures the female adults will accumulate its energy to form the body's structure.

The survivorship curve in this study showed that the chance of survival began to decrease at 14 days after infestation (Fig. 2). It showed that maize is the ideal host for the survivability of $S$. frugiperda. In addition, we also suspect that this condition was also affected by the optimum temperature and humidity for the development of this pest. A similar survivorship curve was also reported by Murua and Virla (2004) in maize and guinea grass, where the death was starting to occur at $14^{\text {th }}$ days and $19^{\text {th }}$ days in guinea grass. Newly invaded species such as $S$. frugiperda is lack of natural enemies in the new habitat. Therefore it may contribute to high survivorship during larvae period (Sisay et al. 2018). Thus, the comprehensive control efforts should be at the beginning from the early stage of maize are important such as intensive population monitoring to implement a control threshold for the justified use of pesticides. Finding pre-adult emergence control measures such as using the botanical pesticide, chemical pesticide, and physical control method are necessary.

The Ro value of $S$. frugiperda in this study was smaller than the result reported by Murua and Virla (2004). The number of female individuals (sex ratio) may affect the value of fecundity, meaning that as the number of female adult increase, the number population will be also likely to increase. The $S$. frugiperda sex ratio in this study was 1: 1.72 (female: male). The survivorship of female adults might also influence the value of Ro. The average longevity of female adults lasted only for 10.06 days, which means the oviposition period was shorter, and the number of eggs produced was less. Net Reproduction Rate (Ro) values indicate the level of compatibility between insects and host plants. The higher the Ro and GRR values, the higher the level of insect compatibility to the host plant. The individual intrinsic rate of increase in the population in a constant environment and the condition of an unlimited resource is illustrated by the r-value. The r-value of 0.22 indicates that in an unlimited condition, individuals in the population can increase by 0.22 times, or they increase by $22 \%$ individuals per day. The intrinsic rate of increase of $S$. frugiperda in maize is higher than several other species of armyworm that have previously existed in Indonesia, such as S. exigua and S. litura. Farahani et al. (2011) reported that the intrinsic rate of increase of $S$. exigua in maize is 0.207. Mardani-Talaei et al. (2016) further reported that the intrinsic rate of increase of $S$. exigua in four varieties of hybrid maize, namely Keynes410, Keynes540, KSC260, KSC400 is $0.131,0.137,0.136$, and 0.102 , respectively. The intrinsic rate of increase of $S$. litura in peanuts under different rearing conditions $\left(25^{\circ} \mathrm{C}\right.$, spring and autumn) in Taiwan were reported at $0.18,0.13$, and 0.15 , respectively (Tuan et al. 2014). Fand et al. (2015) reported the intrinsic rate of increase of $S$. litura was 0.11 in soybeans with a temperature range of $25 \pm 1{ }^{\circ} \mathrm{C}$. Various aspects, which are related to the organism's life cycle, including death, birth, 
and development time, determines the intrinsic rate of increase.

The average value of the generation time (T) and doubling time (DT) were 26.59 and 3.04, respectively. This value was smaller than the results by Murua and Virla (2004). Smaller T value indicates a faster time for an individual in the population to multiply. This also correlates with DT value, that high DT value causes an increase in gross reproduction rate (GRR) and net reproduction rate $(\mathrm{Ro})$ value in a certain time unit.

In conclusion, the fall armyworm $S$. frugiperda tends to distributes in groups consisting of several individuals. The group spreads with a low grouping rate in the field. $S$. frugiperda can develop well in corn in the conditions of temperature and relative humidity $29 \pm 2.1^{\circ} \mathrm{C}$ and $74 \pm$ $10.1 \%$, respectively. This can be seen from the short life cycle and the number of eggs laid by the female. This new pest has the potential to spread rapidly and can cause higher attacks and damage in tropical regions like Indonesia compared to where it originated. Finding effective pre-adult emergence control measures are necessary due to their high survivorship during larvae period under room condition.

\section{ACKNOWLEDGEMENTS}

This research was made possible by technology accompaniment to swamp development in South Sumatra (SERASI). The authors would like to thank Haryanto, Herianto, Sabit, and Rustani as agricultural extension workers at Balai Penyuluhan Pertanian Muara Sugihan Sub-district, Banyuasin District, South Sumatra who provided excellent assistance for allowing us to conduct the study. The authors declare that there is no conflict of interest regarding the publication of this paper. All authors contributed equally to this work

\section{REFERENCES}

Baloch MN, Fan J, Haseeb M, Zhang R. 2020. Mapping Potential Distribution of Spodoptera frugiperda (Lepidoptera: Noctuidae) in Central Asia. Insects 11 (172). 1-10.

Barros E, Torres JB, Ruberson JR, et al. 2010. Development of Spodoptera frugiperda on different hosts and damage to reproductive structures in cotton. Entomol Exp Appl 137: 237-245.

Bateman ML, Day RK, Luke B et al. 2018. Assessment of potential biopesticide options for managing fall armyworm (Spodoptera frugiperda) in Africa. J Applied Entomology 2018 (142): 805-819.

Baudron F, Zaman-Allah MA, Chaipa I et al. 2019. Understanding the factors influencing fall armyworm (Spodoptera frugiperda J.E. Smith) damage in African smallholder maize fields and quantifying its impact on yield. A case study in Eastern Zimbabwe. Crop Protect 120: $141-150$.

Berger D, Walters R, Gotthard K. 2008. What limits insect fecundity? body size and temperature dependent egg maturation and oviposition in a butterfly. Funct Ecol 22: 523-529.

Bulmer MG. 1983. Models for the evolution of protandry in insects. Theor Pop Biol 23 (3): 314-322.

Butler CD and Trumble JT. 2012. Spatial dispersion and binomial sequential sampling for the potato psyllid (Hemiptera: Triozidae) on potato. Pest Manag Sci 68 (6): 865-869.

Chimweta M, Nyakudya IW, Jimu L, et al. 2019. Fall armyworm Spodoptera frugiperda (J.E. Smith)] damage in maize: Management options for flood-recession cropping smallholder farmers. Int J Pest Manag 66 (2): 142-154.

Cock MJW, Beseh PK, Buddie AG, et al. 2017. Molecular methods to detect Spodoptera frugiperda in Ghana, and implications for monitoring the spread of invasive species in developing countries. Sci Rep 7 (4103): 1-10.

Combs RL and Valerio JR. 1980. Biology of the fall armyworm on four varieties of Bermudgrass when held at constant temperatures Environ Entomol 9 (4): 393-396.

Day R, Abrahams P, Bateman M, et al. 2017. Fall armyworm: impacts and implications for Africa. Outlooks Pest Manag 28 (5): 196-201.

Fand BB, Sul NT, Bal SK, et al. 2015. Temperature impacts the development and survival of common cutworm (Spodoptera litura): Simulation and visualization of potential population growth in India under warmer temperatures through life cycle modelling and spatial mapping. PLoS ONE 10 (4): e0124682. DOI: 10.1371/journal.pone.0124682. eCollection 2015.

Farahani S, Naseri B, Talebi AS. 2011. Comparative life table parameters of the beet armyworm, Spodoptera exigua (Hubner) (Lepidoptera, Noctuidae) on five host plants. J Entomol Res Soc 13 (1): 91-101.

Goergen G, Kumar PL, Sankung SB, et al. 2016. First report of outbreaks of the fall armyworm Spodoptera frugiperda (J E Smith) (Lepidoptera, Noctuidae), a new alien invasive pest in West and Central Africa. PLoS ONE 11 (10): e0165632. DOI: 10.1371/journal.pone.0165632.

Hay-Roe MM, Meagher RL, Nagoshi RN, et al. 2016. Distributional patterns of fall armyworm parasitoids in a cornfield and a pasture field in Florida. Biol Control 96: 48-56.

Hutasoit RT, Triwidodo H, Anwar R. 2017. Biology and demographic statistics of Thrips parvispinus Karny (Thysanoptera: Thripidae) in chili pepper (Capsicum annuum Linnaeus). J Entomologi Indonesia 14 (3): 51-60. [Indonesian].

Iwao S. 1968. A new method for analyzing the aggregation pattern of animal population. Res Popul Ecol 10: 1-20.

Iwao S. 1975. A new method of sequential sampling to classify population relative to a critical density. Res Popul Ecol 16: 201-288.

Kergoat GJ, Dorothy PP, Bruno P Le Ru et al. 2012. Disentangling dispersal, vicariance and adaptive radiation patterns: a case study using armyworms in the pest genus Spodoptera (Lepidoptera: Noctuidae). Mol Phylogenet Evol 65: 855-870.

Kondidie DB. 2011. Genetic Variability and Gene Flow of the Fall Army Worm Spodoptera frugiperda (J.E. Smith) in the Western Hemisphere and Susceptibility to Insecticides. [Dissertation]. University of Nebraska-Lincoln. Lincoln, Nebraska.

Kumela T, Simiyu J, Sisay B, et al. 2018. Farmers' knowledge, perceptions, and management practices of the new invasive pest, fall armyworm (Spodoptera frugiperda) in Ethiopia and Kenya. Int J Pest Manage 65 (1): 1-9.

Kuno E. 1969. A method of sequential sampling to obtain the population estimates with a fixed level of precision. Res Popul Ecol 11: 127-136.

Lestari P, Adriyana B, Fitriana Y et al. 2020. Identification and genetic diversity of Spodoptera frugiperda in Lampung Province, Indonesia. Biodiversitas 21 (4): 1670-1677.

Maharani Y, Dewi VK, Puspasari LT, et al. 2019. Cases of fall armyworm Spodoptera frugiperda J. E. Smith (Lepidoptera: Noctuidae) attack on maize in Bandung, Garut and Sumedang District, West Java. J Cropsaver 2 (1): 38-46.

Mardani-Talaei M, Nouri-Ganbalani G, Baseri N, et al. 2016. Comprative life table parameters of the Spodoptera exigua (Hübner) (Lepidoptera: Noctuidae) on corn hybrids under laboratory conditions. J Entomol Soc Iran 35 (4): 17-27.

Mardani-Talaei M, Nouri-Ganbalani G, Naseri B, Hassanpour M. 2012. Life history studies of the beet armyworm, Spodoptera exigua (Hübner) (Lepidoptera: Noctuidae) on 10 corn hybrids. J Entomol Res Soc 14 (3): 9-18.

Montezano DG, Specht A, Sosa-Gomez DR. 2018. Host Plants of Spodoptera frugiperda (Lepidoptera: Noctuidae) in the Americas. African Entomol 26 (2): 286-300.

Murua G and Virla E. 2004. Population parameters of Spodoptera frugiperda (Smith) (Lep.: Noctuidae) fed on corn and two predominant grasess in Tucuman (Argentina). Acta Zool Mexicana 20 (1): 199-210.

Nagoshi RN, Meagher RL, Hay-Roe M. 2012. Inferring the annual migration patterns of fall armyworm (Lepidoptera: Noctuidae) in the United States from mitochondrial haplotypes. Ecol Evol 2 (7): 14581467. 
Nava DT, Nicolis O, Opazo MAU, et al. 2018. Statistical methods for identifying anisotropy in the Spodoptera frugiperda spatial distribution. Spanish J Agric Res 16 (1): 1-10.

Nonci N, Kalqutny SH, Mirsam H, Muis A, Azrai M, dan Aqil M. 2019 Pengenalan Fall Armyworm (Spodoptera frugiperda J.E. Smith) Hama Baru Pada Tanaman Jagung di Indonesia. Balai Penelitian Tanaman Serealia, Maros. [Indonesian]

Price PW. 1997. Insect Ecology. 3rd ed. John Wiley \& Sons, New York.

Rios ES, Martins ICF, de Noronha MP, et al. 2014. Spatial distribution of Spodoptera frugiperda in the wasteland of southern Pernambuco state, Brazil. Rev Cienc Agrar 57 (3): 297-304.

Saldamando CI and Velez-Arango AM. 2010. Host Plant Association and Genetic Differentiation of Corn and Rice Strains of Spodoptera frugiperda Smith (Lepidoptera: Noctuidae) in Colombia. Neotropical Entomol 39 (6): 921-929.

Sharanabasappa, Kalleshwaraswamy CM, Asokan R, et al. 2018. First report of the Fall armyworm, Spodoptera frugiperda (J E Smith) (Lepidoptera: Noctuidae), an alien invasive pest on maize in India. Pest Manag Hortic Ecosys 24 (1): 23-29.

Sharanabasappa, Kalleshwaraswamy CM, Maruthi MS, et al. 2018 Biology of invasive fall armyworm Spodoptera frugiperda (J.E. Smith) (Lepidoptera: Noctuidae) on maize. Indian J Entomol 80 (3): 540-543.

Sidana J, Singh B, Sharma OP. 2018. Occurrence of the new invasive pest, fall armyworm, Spodoptera frugiperda (JE Smith) (Lepidoptera:
Noctuidae), in the maize fields of Karnataka, India. Curr Sci India 115 (4): 621-623.

Sisay B, Simiyu J, Malusi P, Likhayo P, Mendesil E, Elibariki N, et al. 2018. First report of the fall armyworm, Spodoptera frugiperda (Lepidoptera: Noctuidae), natural enemies from Africa. J Appl Entomol 142 (8): 800-804.

Sisay B, Tefera T, Wakgari M, et al. 2019. The efficacy of selected synthetic insecticides and botanicals against fall armyworm, Spodoptera frugiperda, in Maize. Insects 10 (45):1-14.

Tuan SJ, Lee CC, Chi H. 2014. Population and damage projection of Spodoptera litura (F.) on peanuts (Arachis hypogaea L.) under different conditions using the age stage, two-sex life table. Pest Manag Sci 70: 805-813.

Vilarinho EC, Fernandes OA, Hunt TE, et al. 2011. Movement of Spodoptera frugiperda adults (Lepidoptera: Noctuidae) in maize in Brazil. Florida Entomologist 94 (3): 48-488.

Wade MJ, Fitzpatrick CL, Lively CM. 2018. 50-year anniversary of Lloyd's "mean crowding": Ideas on patchy distributions. J Anim Ecol 87: 1221-1226.

Widiarta IN. 1995. Rancangan pengambilan contoh dan model populasi wereng hijau, Nephotettix virescens (DISTANT) (Hemiptera:Cicadellidae). Buletin Hama dan Penyakit Tumbuhan 8 (1): 1-8. [Indonesian] 